\title{
Plan of large-scale shaking table tests using E-Defense for liquefaction of reclaimed ground
}

\author{
Kazuo Tani \\ Research Fellow, E-Defense, National Research Institute for Earth Science and Disaster Prevention, \\ 1501-21, Nishikameya, Mitsuta, Shijimicho, Miki, Hyogo 673-0515, Japan.
}

\begin{abstract}
Development of effective and economical technologies to evaluate liquefaction potentials and to prevent liquefaction damages is one of the most pressing issues, which were strongly addressed by the Japanese Geotechnical Society after the serious liquefaction damages occurred in the 2011 Tohoku earthquake. In this paper, a series of large-scale shaking table tests is proposed to obtain the valuable database of case histories for the theme of liquefaction of young reclaimed ground. Using the world largest shaking table facility called E-Defense, this plan aims the new idea of 'prototype tests' rather than the conventional 'model tests'.
\end{abstract}

Keywords: shaking table, liquefaction, reclaimed ground, prototype test, similarity rule

\section{NECESSITY OF LARGE-SCALE EXPERIMENTS ON SOIL LIQUEFACTION}

Significant damages of houses caused by soil liquefactions in the 2011 off the Pacific coast of Tohoku Earthquake prompted research and development on effective evaluation of liquefaction potential by simple geotechnical investigations and on various economical countermeasures. To put these new technologies into practice for prevention and mitigation of damages, their effectiveness and applicability should be appropriately verified. For the evaluation of liquefaction potential, however, comparisons have only been made with the conventional methods and/or case histories of soil liquefactions. Thus, no direct verification has been made so far. Moreover, for the liquefaction countermeasures, although some small-scale model tests in the centrifuge and moderate-scale model tests in a gravitational field have been conducted, appropriate modeling of execution works of various ground improvements are impossible. Therefore, large scale shaking table tests are best suited for their suitable verification using prototype-scale ground where various geotechnical investigations and ground improvements can be conducted realistically as in the field practice.

\section{SIGNIFICANCE OF 'PROTOTYPE TESTS' USING E-DEFENSE OF NIED}

E-Defense of National Research Institute for Earth Science and Disaster Prevention (NIED) is the world largest shake table constructed in 2004 near Kobe, Japan. The author proposed a new concept of 'prototype tests' for geotechnical experiments using this gigantic facility as a replacement of traditional concept of 'model tests' (Tani, 2013). For suitable geotechnical experiments as 'prototype tests' that require no similarity rule, the following three features are presented.

1) Rather than natural ground of simple and uniform nature, artificial ground of complicated composition and structures should be preferably studied.

2) Preparation of the ground, execution of geotechnical investigations and various geotechnical works, and history of external actions including seismic effects should be reproduced as real as possible.

3) Purposes of the study are set to evaluate applicability of geotechnical designs and numerical modeling.

Furthermore, two projects were suggested as typical candidate experiments; the one is liquefaction of reclaimed ground, and the other is failure of retaining structures and/or embankments. When the former project is assigned to investigate the occurrence of soil liquefaction and the behaviors of foundations and buried structures on and in the liquefied ground, the following factors are important as the experimental conditions;

1) Grading and particle shapes of the geomaterials, and stress levels and stress histories, as related to generation of excess pore water pressure,

2) Permeability of the ground as related to dissipation of excess pore water pressure,

3) Ground structures (heterogeneous geological structures such as bedforms, stratifications and so forth) as related to the behaviors of the liquefying/liquefied ground (e.g., sand boils), 
4) Methods of soundings as related to evaluation of liquefaction potential, and

5) Execution methods of geotechnical works as related to liquefaction countermeasures, and so forth.

If the "model tests" of a reduced scale are carried out, the relevant similarity rule taking into account the above various factors are extremely complex. It is a common practice that attentions are only paid to those a few dominant and controllable factors, while the rests are unavoidably ignored. Thus, imperfect similarity rules ought to be applied for translation of the observed behaviors of model ground to the prototype behaviors of interest for interpretation. However, if the 'prototype tests' which are not associated with similarity rules or scaling are attempted, the observed behaviors of the test ground in the experiments are the subject of study. In addition, in the 'prototype tests' using E-Defense, we can conduct all the geotechnical investigations for evaluation of liquefaction potential and most of the ground improvement works of moderate-scales that do not involve the use of excessively huge machineries.

\section{EXPERIMENTAL PROJECT FOR SOIL LIQUEFACTION OF RECLAIMED GROUND}

\subsection{Purposes of the experiments and policies of enforcement}

The purposes of the experiments are to obtain high quality data for verification of the relevant geotechnical designs and geotechnical modeling. Focuses of interest are placed on the following three themes;

1) To develop simple geotechnical investigations for evaluation of liquefaction potential,

2) To develop economical liquefaction countermeasures effective for disaster mitigation, and

3) To develop sophisticated numerical modeling for deformations of liquefied ground.

Moreover, these experiments shall be implemented in accordance with the following four policies.

1) To introduce the idea of 'prototype tests'

To maximize the features of the huge shaking table of E-Defense, the 'prototype tests' should be implemented. This new concept implies that the tests are not bound by common modeling rules such as idealizations, simplification and downsizing which are premised in the 'model tests'. To achieve this, all the processes of field events, including reclamation of the ground, geotechnical investigations, execution of geotechnical works, and shaking to cause soil liquefactions, should be reproduced in the experiments.

2) To contribute to prevention and mitigation of damages caused by soil liquefactions

Promising technologies for simple geotechnical investigations for evaluation of liquefaction potential and economical liquefaction countermeasures are to be appropriately selected for this study. Experimental conditions and instrumentations are carefully planned so that effectiveness and applicability of these technologies can be appropriately evaluated.

3) To contribute extensively and permanently to research and development in geotechnical engineering field

Details of complete processes of the experiments are precisely measured, described and published. These valuable information assets should be used permanently and extensively as "benchmark" for verification of future technologies. The initial and boundary conditions are carefully set so that they are compatible or harmonized with the geotechnical designs and numerical modeling of interest.

4) To mobilize the power of researchers and engineers

A research committee will be established in an academic society where all the researchers and engineers who are specialized in soil liquefactions can participate, collaborate and cooperate without any restrictions. As one of the activities of this research committee, a series of workshops will be held to stimulate discussions and to widely publicize the relevant outcomes.

\subsection{Characteristic features of the experiments}

Figure 1 schematically shows the proposed experiments. Some of the characteristic features are discussed below (Tani \& Kubota, 2014).

(1) Principally, the test ground will be shaken in a horizontal direction (uniaxial excitation) in view of the practical geotechnical designs. The loading program is comprised of combinations of the three patterns; stepwise increasing loading (repeated loading of the basic seismic wave with increasing amplitudes until severe soil liquefaction is observed), prolonged loading (seismic waves of long duration up to several minutes assuming large subduction zone earthquakes), and combined loading (combination of the main-shock and the succeeding aftershocks).

(2) A new type of rectangular soil container of simple-shear will be developed to conduct high quality experiments sufficient to verify the sophisticated numerical modeling. Laminated multi-layer square frames are supported separately to prevent unwanted displacement components other than the shaking direction.

(3) The test ground represents young reclaimed ground in coastal areas. Its thickness is set no less than 10 meters to allow execution of various geotechnical investigation techniques and liquefaction countermeasures. The length and the width are set 10 meters and 4 meters respectively, as considering the lifting capacity of the available crane, $8,000 \mathrm{kN}$, the payload of the shaking table, $12,000 \mathrm{kN}$, and the workability of the various geotechnical works. This test ground will be prepared by pump-convey-spread system as similar to the field reclamation practices to reproduce the characteristic features of young reclaimed ground of heterogeneous, non-uniform and 


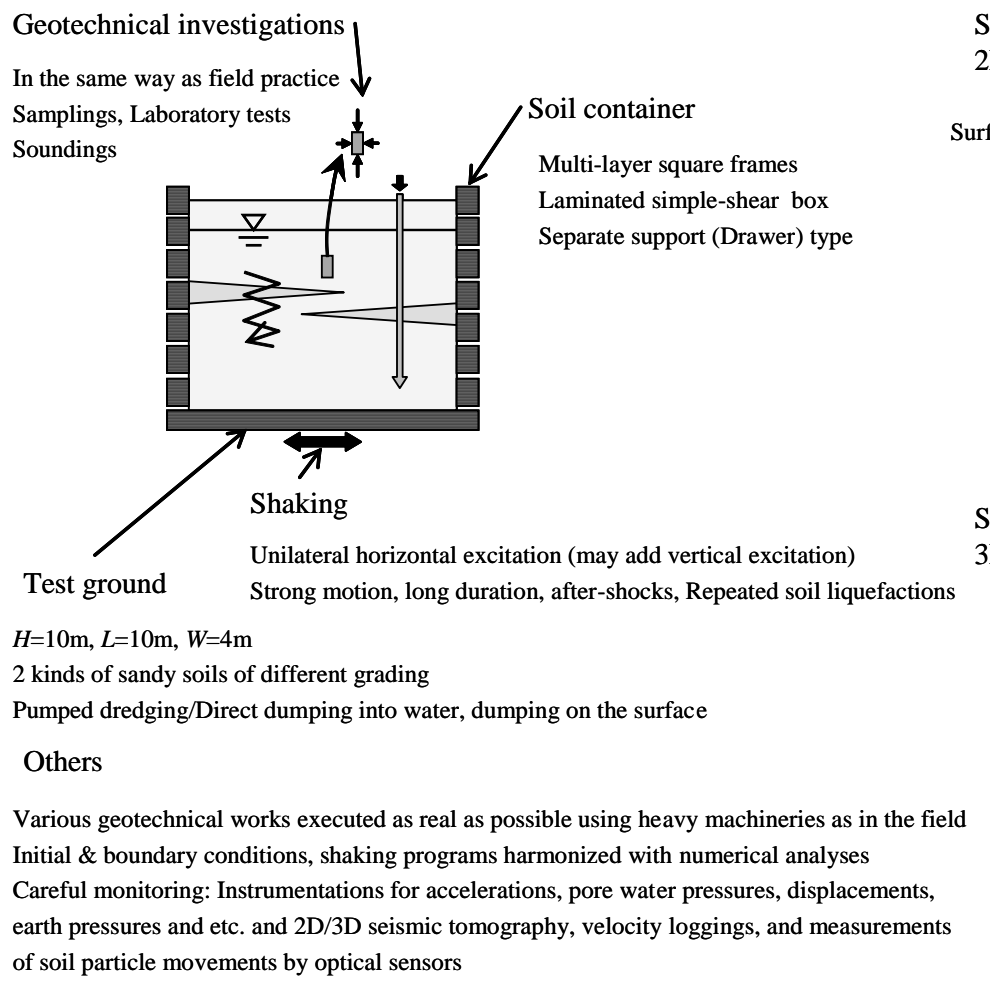

Series 1 for evaluation methods of liquefaction potential 2D (Plane strain) condition

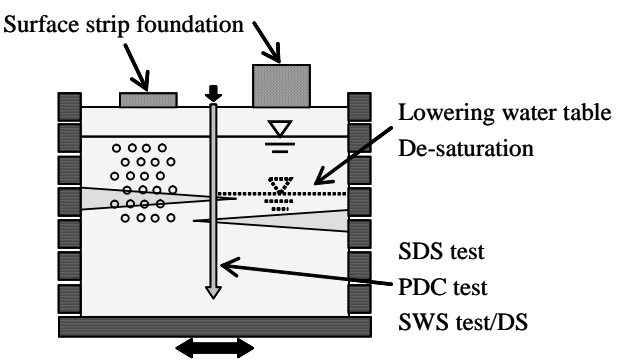

Series 2 for liquefaction countermeasure 3D condition

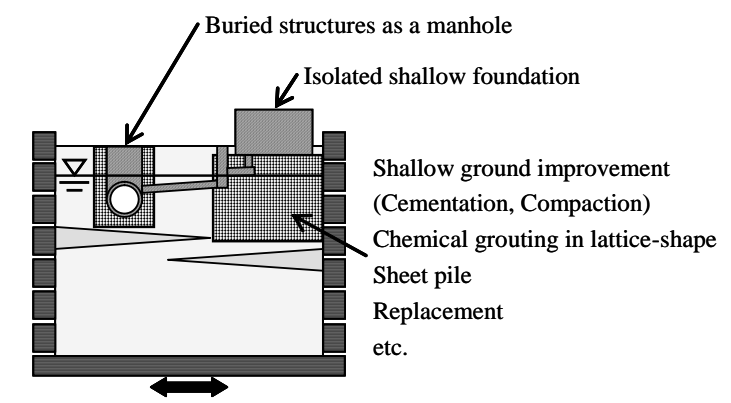

Fig.1. Features of experiments.

extremely loose natures. To verify the evaluation methods of liquefaction potential for geomaterials of wide variety, two kinds of sands of different grading characteristics are used.

(4) Two series of experiments will be conducted. The first series (hereinafter, Series 1) whose main theme is the evaluation methods of liquefaction potential, is a two-dimensional problem (in a plane strain condition) using two surface strip foundations. Whereas the second series (hereinafter, Series 2) whose main theme is the liquefaction countermeasures, is a three-dimensional problem using an isolated shallow foundation and buried structures such as a manhole and sewer facilities.

(5) All the geotechnical investigations can be conducted in exactly the same way as field practices using the probes, instruments and machineries for the field applications. Furthermore, the execution of geotechnical works of various liquefaction countermeasures are carried out in as similar way as possible to the field practices.

(6) The various conditions of the experiments, e.g., the initial conditions, the boundary conditions and the shaking programs, are carefully set so that they are harmonized with those of numerical modeling. Various instrumentations for monitoring the experiments are designed to facilitate detailed comparisons with the results of numerical analyses. Moreover, two- and/or three-dimensional seismic tomography, velocity loggings and some other new measuring techniques will be attempted to observe all the liquefaction processes of the test ground.

\subsection{Flow of the experimental project}

Figure 2 shows the flow of the experimental project. After the preparation of the experiments, two series of experiments will be carried out. A few workshops will be held in accordance with progress of this project.

In the first year, development of the soil container, selection of the sands, practice tests to establish experimental methods such as for preparation of the test ground, laboratory tests on the selected sands and preliminary numerical analyses are carried out for preparation of the experiments. Each series consists of preliminary tests, vibration tests on the shaking table,

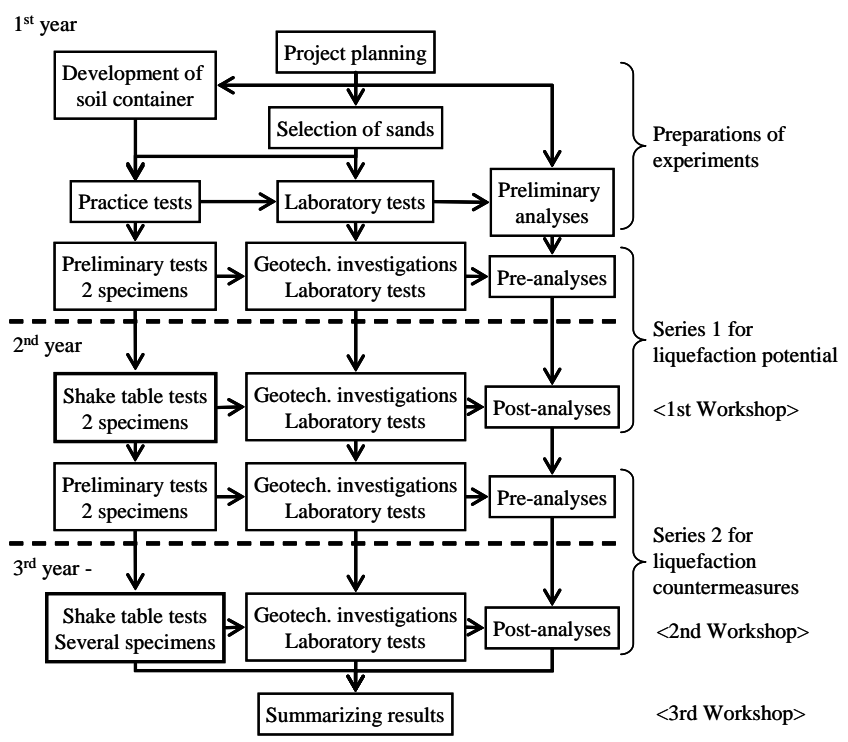

Fig.2. Flow of the experimental project. 


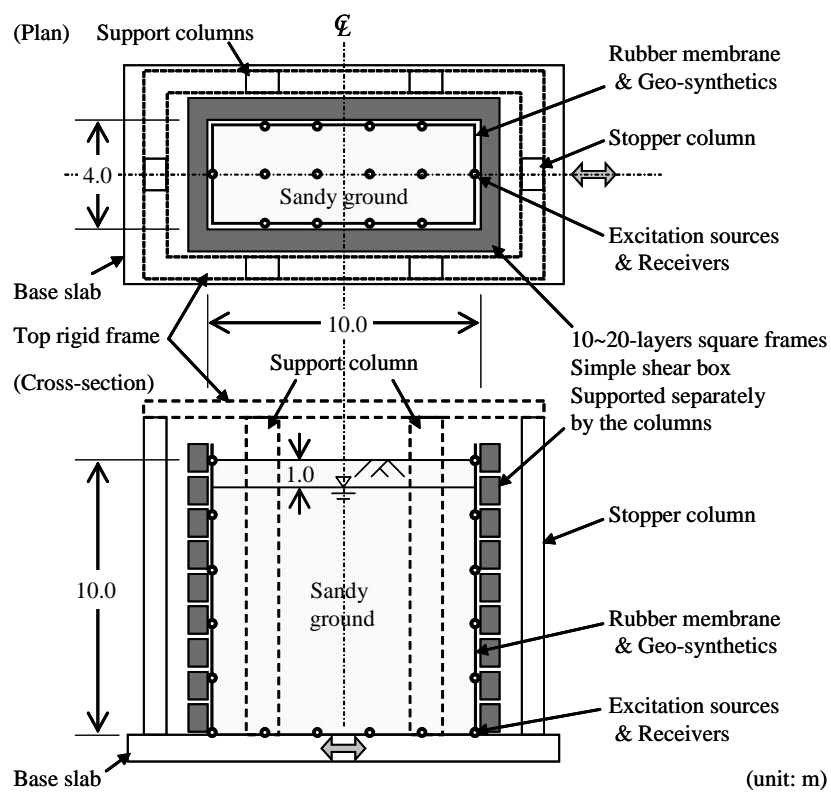

Fig.3. Soil container.

geotechnical investigations, laboratory tests, and preand post-analyses. Preliminary tests will be conducted to obtain various information of the test ground required for pre-analyses and to study the workability of the experimental works. Using the ground information obtained by the practice tests, the preliminary analyses will be done to examine the details of the test program. Furthermore, using the ground information obtained by the preliminary tests, the pre-analyses will be done, and using the ground information obtained by the vibration tests, the post-analyses will be done.

For Series 1 to study liquefaction potential, two vibration tests will be done in the second year for each two kinds of sands. For Series 2 to study liquefaction countermeasures, several vibration tests will be done in the third year for individual method using the appropriate sand.

\section{SPECIMEN}

The specimens consist of a soil container, a test ground, surface and buried structures and improved ground.

\subsection{Soil container}

Figure 3 illustrates the proposed new soil container of simple-shear box (Tani, 2014). The basic configuration is a basement, multi-layer square frames that can slide horizontally in the vibrating direction, four columns to support these sliding frames, two columns for stoppers, rubber membrane of watertight, and the top rigid frame connecting all the six columns.

The individual sliding frame is supported separately by the four columns to avoid accumulation of unwanted mechanical plays for the upper frames which is one of the most serious disadvantages of the conventional soil containers of laminated piling frames. Four pairs of linear rails and rollers are used to ensure ideally uniaxial sliding in the horizontal plane without friction. As many as 10 to 20 sliding frames are equipped to accommodate continuous shear deformations along the vertical side sections. To avoid any constraints on the test ground, the weight of the sliding frame is made as light as possible, preferably less than one-tenth of that of the ground mass inside.

The rubber membrane is cylindrical in shape, and fixed tightly inside the soil container to prevent leakage of water and soil particles. Thick cushion members are not installed on the sidewall for smoothing the discontinuous deformations, because the boundary conditions may become unclear for numerical modeling. Instead, a thin layer of geo-synthetics is equipped for protection of the rubber membrane.

\subsection{Test ground}

The test ground of 10 meter thick will be prepared by pump/convey/spread system. The sands transported to the soil container will be dumped above the water in early stage and on the ground surface in later stage. The ground water table is set 1 meter deep, thereby 9 meters of a liquefiable layer. Although focus of interest is placed on the young reclaimed ground, which was landfilled less than 50 years ago, the aging effect on soil liquefaction characteristics is still an important issue. This time effect may be simulated appropriately by equivalent over-consolidation histories.

Two kinds of sands of different grading characteristics will be used. The one is a coarser sand of degraded weathered granite, called 'Masa', assuming the landfill materials used in the Kobe port areas. Whereas the other is a finer sand of marine clastic sand, assuming those used in the Tokyo Bay areas.

\subsection{Surface and buried structures, and improved ground}

In Series 1, two surface foundations of concrete (the unit weight $23 \mathrm{kN} / \mathrm{m}^{3}$ ) will be placed on the test ground, as shown in Figure 4. As assuming two-dimensional problem of plane strain condition, they are strip foundations of width 1.0 meter. Their heights are set $0.43 \mathrm{~m}$ (weight $40 \mathrm{kN}$ ) and $1.30 \mathrm{~m}$ (weight $119 \mathrm{kN}$ ), respectively, as assuming the bearing pressures, $10 \sim 30 \mathrm{kN} / \mathrm{m}^{2}$, of ordinary houses and small-scale structures. Among various liquefaction countermeasures, dewatering method and desaturation method may be attempted in Series 1, because these methods can be applied on the same test ground and the relevant geotechnical works are neither difficult nor time consuming.

In Series 2, surface as well as buried structures will be installed in each test ground prepared for individual liquefaction countermeasure method, as shown in Figure 5. As assuming three-dimensional problem, the surface structure is a shallow isolated foundation of 


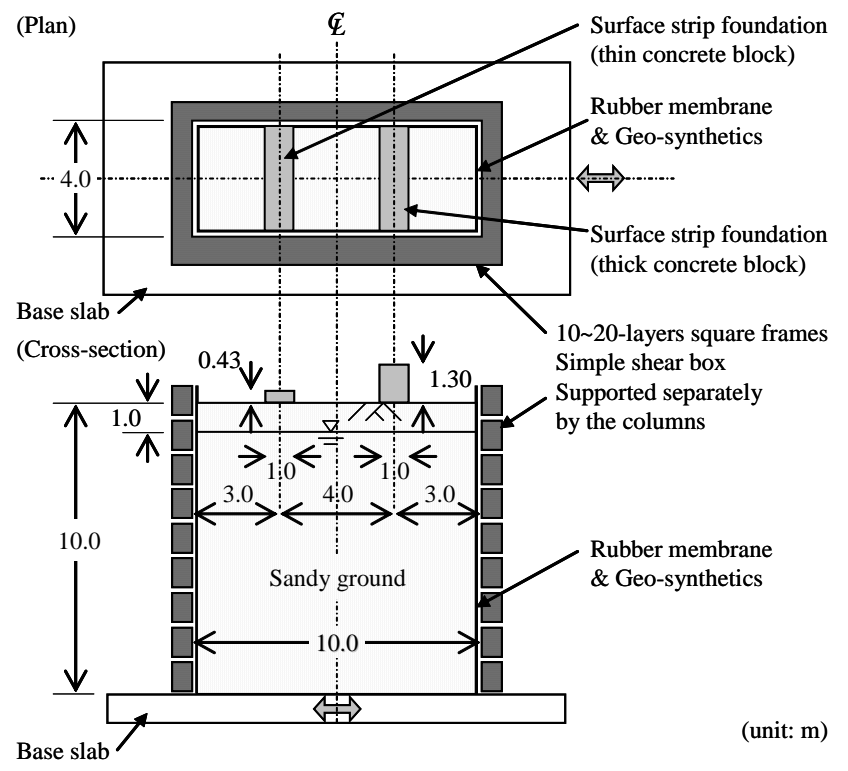

Fig.4. Experimental set-up for Series 1.

concrete and the buried structures are a manhole and some sewer facilities. Appropriate liquefaction countermeasures are selected among shallow ground improvement methods of cementation and compaction, a chemical grouting method in lattice-shape by high-pressure jet grouting, a sheet-pile method, a replacement method using crusher run and so forth. For these methods, all the processes of geotechnical works including planning, investigation, design and construction should be executed reproducing the field practices as closely as possible.

\section{GEOTECHNICAL INVESTIGATIONS AND LABORATORY TESTS ON GEOMATERIALS}

In order to obtain ground information necessary for numerical analyses, geophysical explorations, soundings, and samplings for laboratory tests will be conducted in the test ground. Various soundings and samplings should be conducted in exactly the same way as in the field practices. For these geotechnical investigations, a platform will be mounted on the top rigid frame above the soil container.

\subsection{Geophysical explorations}

By seismic tomography and velocity loggings, $\mathrm{S}$-wave as well as $\mathrm{P}$-wave velocities, $V_{\mathrm{s}} \& V_{\mathrm{p}}$, are measured in the test ground. The values of $V_{\mathrm{s}}$ and $V_{\mathrm{p}}$ are to evaluate the changes of the shear moduli and the saturation states, respectively. Continuous measurements will be done during and after the excitations of the shaking table, to monitor generation and dissipation of the excess pore water pressures, degradation and recovery of the ground's stiffness, and migrations of the interstitial water.

\subsection{Soundings}

In the preliminary tests, standard penetration test $(\mathrm{SPT})^{*}$, electric cone penetration test (CPTU)*,

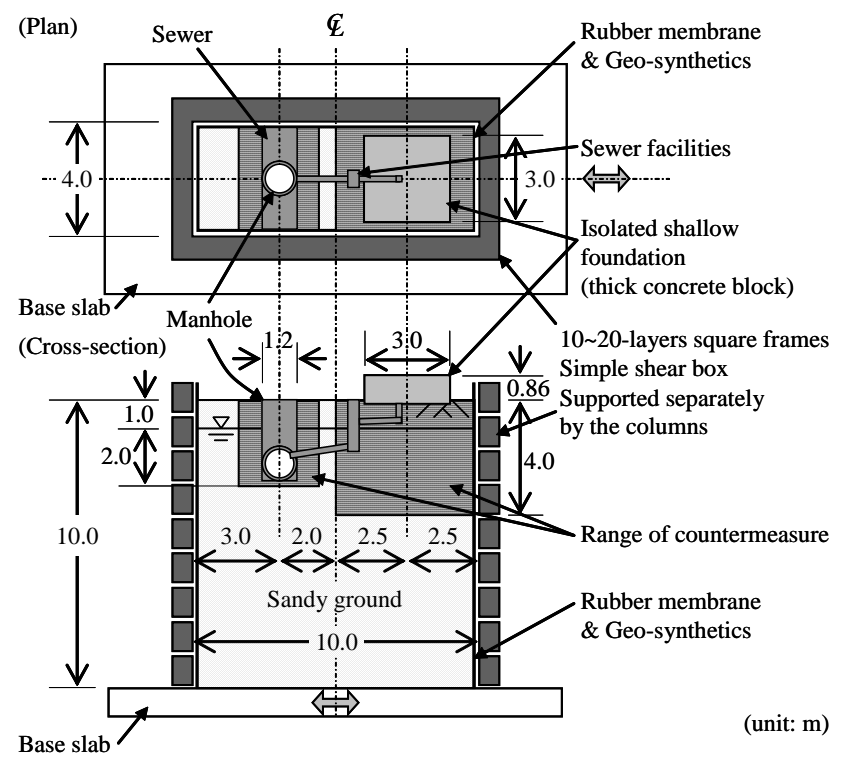

Fig.5. Experimental set-up for Series 2.

Swedish weight sounding (SWS) test*, screw-driver sounding (SDS) test*, piezo-drive cone (PDC)* test, and other dynamic cone penetration tests (for example, automatic ram sounding (DPSH-A) test or mini ram sounding (mini-DCP) test and etc.) will be carried out. However, in the shaking table tests, those limited investigations relevant to the evaluation of liquefaction potential, as denoted by the superscript *, will be conducted only after significant soil liquefaction takes place, so as not to disturb the test ground excessively by these investigations.

\subsection{Samplings}

High quality sampling from very loose sand deposits is extremely challenging. Attempts will be made to obtain soil samples with least disturbances by triple-tube sampling (TTS) method, tube sampling method using thick polymer solution (GPS), block sampling (BS) method, and some other multi-tube sampling methods.

\subsection{Laboratory tests on geomaterials}

As tests for physical properties, the density test of soil particles, the test for particle size analysis and the maximum and minimum densities test of gravels and sands will be done. Moreover, as tests for mechanical properties, the cyclic undrained triaxial test (of stressand strain-control), the consolidated-drained (CD) and consolidated-undrained (CU) triaxial compression tests, cyclic torsional shear tests, permeability tests (including for the unsaturated state), water retention tests, and compaction tests will be done. The relevant test conditions (e.g., drainage conditions, stress paths, loading rates and so forth) and instrumentation methods should be determined appropriately considering harmonization with the numerical modeling for the mechanical behaviors of geomaterials and at the boundaries between the geomaterials and the structures. 


\section{INSTRUMENTATIONS}

\subsection{Measurements on the soil container}

To monitor the behaviors of the individual shear frame of soil container, other than the measurements by accelerometers and displacement transducers, the movements of markers placed on the external sides will be recorded by high-precision video-cameras. Furthermore, excitation devices (vibrators/seismic sources) and seismometers (receivers) will be mounted on the inner surface of soil container for the seismic tomography to obtain the 2D/3D images of $V_{\mathrm{p}}$ and $V_{\mathrm{s}}$ distributions within the test ground. For these seismic explorations, the accelerometers installed in the test ground will also be used.

\subsection{Measurements on and in the test ground}

In addition to the measurements by the accelerometers and displacement transducers, the displacements of markers on the test ground and the various surface deformations such as sand boils will be recorded by video shoot. Inside the test ground, measurements by the pore water pressure transducers and accelerometers will be done. For some special instrumentations, velocity transducers, settlement sensors, inclinometers, RI sensors for soil moisture measurements may also be used.

\subsection{Measurements on the structures}

Similar to the ground surface, measurements by the accelerometers and displacement transducers as well as video shoot will be done on the structures. In addition, subgrade reactions/stresses and water pressures on the boundaries such as the bottom surface of the foundations will be measured by earth pressure gauges and pressure transducers, respectively.

\section{SUMMARY}

A series of large-scale shaking table tests is proposed to obtain the valuable database of case histories for the theme of liquefaction of young reclaimed ground. Using the world largest shaking table facility called E-Defense of National Research Institute for Earth Science and Disaster Prevention (NIED), this plan aims the new idea of 'prototype tests' rather than the conventional 'model tests'. The purposes of experiments, the policy of enforcement and the experimental designs are discussed. The characteristic features of these 'prototype tests' are summarized as follows.

(1) Significantly heterogeneous and non-uniform nature of very loose test ground, of 10 meters thick, will be prepared by pumping system as exactly reproducing the young reclaimed ground in coastal areas. Two kinds of soils, coarse and fine sands, will be used to study the applicability of various evaluation methods of liquefaction potential for a wide range of grading characteristics.

(2) For the purpose to characterize the test ground, various sounding techniques, including standard penetration tests, cone penetration tests and various weight soundings, and various sampling methods will be conducted in the same way as in the field practices.

(3) A new soil container of laminated simple-shear box with multi-layer square frames will be developed. Each sliding frame is supported separately to avoid accumulation of unwanted mechanical plays for the upper frames which is one of the most serious disadvantages of the conventional multi-layered shear box of piling frames.

(4) Various geotechnical works including cutting/excavation, filling, compaction, excavation, ground improvements and installations of reinforcements will be executed in as similar way as possible to the field practices using the real construction machineries. This is to reproduce the actual states of complicated and uncertain construction conditions and procedures which have never been properly modeled in conventional small-scale model tests.

(5) Some novel measuring and instrumentation techniques will be attempted to monitor the liquefying/liquefied ground. Two-dimensional as well as three-dimensional seismic tomography will be conducted to obtain distributions of elastic wave velocities in the test ground.

More detailed information can be found in the reference (Tani \& Kubota, 2014). For such a large-scale experimental project, big research fund with appropriate support are mandatory. At the moment, by February 2015, it has not been confirmed whether this proposal will be accepted or not.

\section{REFERENCES}

1) Tani, K. (2013): Suggestions for the use of E-Defense to disaster prevention in geotechnical engineering, Proc. 58th Sym. on Geotechnical Engineering, JGS, 199-202 (in Japanese).

2) Tani, K. and Kubota, K. (2014): Plan of E-Defense experiments for liquefaction of reclaimed ground, Proc. 14th Japan Earthquake Engineering Sym., pp.2445-2454 (in Japanese)

3) Tani, K. (2014): Study on shear box to be used for shaking table tests on liquefaction of reclaimed lands, Proc. 49th JGS Sym., JGS, 1659-1660 (in Japanese). 